\title{
Non Ruptured MCA Aneurysms Presenting with Insular Related Symptoms
}

\author{
Ramez Malak, Dank Khoa Nguyen, Michel W. Bojanowski
}

\begin{abstract}
Objective: To present a new semiological description of unruptured middle cerebral artery (MCA) aneurysms. Methods: We present a series of three MCA aneurysms presenting with progressive or paroxystic somatosensory symptoms in combination with visceral, motor, language or autonomic symptoms. Results: A surgical approach was proposed for two aneurysms, and both patients experienced complete resolution of their symptoms. The third aneurysm was successfully excluded by endovascular coiling but the symptoms persisted. Conclusions: To our knowledge this is the first description of unruptured aneurysms presenting with insular-related symptoms.
\end{abstract}

RÉSUMÉ: Symptômes propres à l'insula comme symptômes d'appel d'anévrismes non rompus de l'ACM. Objectif : Nous présentons une nouvelle description séméiologique des anévrismes non rompus de l'artère cérébrale moyenne (ACM). Méthodes : Nous présentons une série de trois patients porteurs d'anévrismes de l'ACM dont les symptômes d'appel étaient des symptômes somesthésiques progressifs ou paroxystiques accompagnés de symptômes viscéraux, moteurs, du langage ou neuro-végétatifs. Résultats : Une approche chirurgicale a été proposée pour traiter deux des anévrismes et les symptômes ont disparu chez les deux patients. Le troisième anévrisme a été exclu avec succès par embolisation endovasculaire de microspires (coils), mais les symptômes ont persisté. Conclusions : Il s'agit, à notre connaissance, de la première description de patients porteurs d'anévrismes intacts dont les symptômes d'appel étaient des symptômes propres à l'insula.

Can. J. Neurol. Sci. 2010; 37: 219-222

Unruptured intracranial aneurysms are usually asymptomatic, detected incidentally on brain imaging. Larger unruptured aneurysms however can present with symptoms related to compression. Examples include chiasmatic compression by internal carotid or anterior communicating artery aneurysms, intracavernous aneurysms causing ophtalmoplegia and facial pain, and aneurysms of the posterior communicating artery producing third nerve palsy. We present three cases of middle cerebral artery (MCA) aneurysm who presented with bilateral paresthesiae and autonomic symptoms due to either epileptic activity or mass effect on the insular cortex.

\section{Case Series}

Case 1: A 50-year-old female complained of dry mouth, throat constriction, palpitations and left arm paresthesiae for the previous three days. The paresthesiae progressed over the next five weeks to involve the left leg, perioral area and finally became bilateral, involving the four limbs. Her neurological exam was normal. Cardiac workup was normal. Cerebral magnetic resonance imaging (MRI) and angiography demonstrated a right MCA aneurysm measuring $11 \mathrm{~mm}$ lying over the insula. Electroencephalogram (EEG) was not performed. Following surgical clipping of the aneurysm, the patient has been symptom free for four years since surgery, except for one episode of mild left arm paresthesia occurring on the fourth day after surgery (Figure 1).

Case 2: A 55-year-old female presented with a four-year history of daily episodic paresthesiae lasting two to ten minutes, involving mainly the right limbs, less frequently the left limbs and occasionally both sides. Some episodes were severe enough to wake the patient at night. Other symptoms such as nausea,

From the Divisions of Neurosurgery (RM, MWB), and Neurology (DKN), NotreDame Hospital, Centre Hospitalier de l'Université de Montréal, Montreal, Quebec, Canada.

Received September 8, 2009. Final Revisions Submitted October 23, 2009. Correspondence to: Michel W. Bojanowski, Department of Neurosurgery,

Notre-Dame Hospital, Centre Hospitalier de l'Université de Montréal, 1560 Sherbrooke Street East, Montreal, Quebec, H2L 4M1, Canada. 


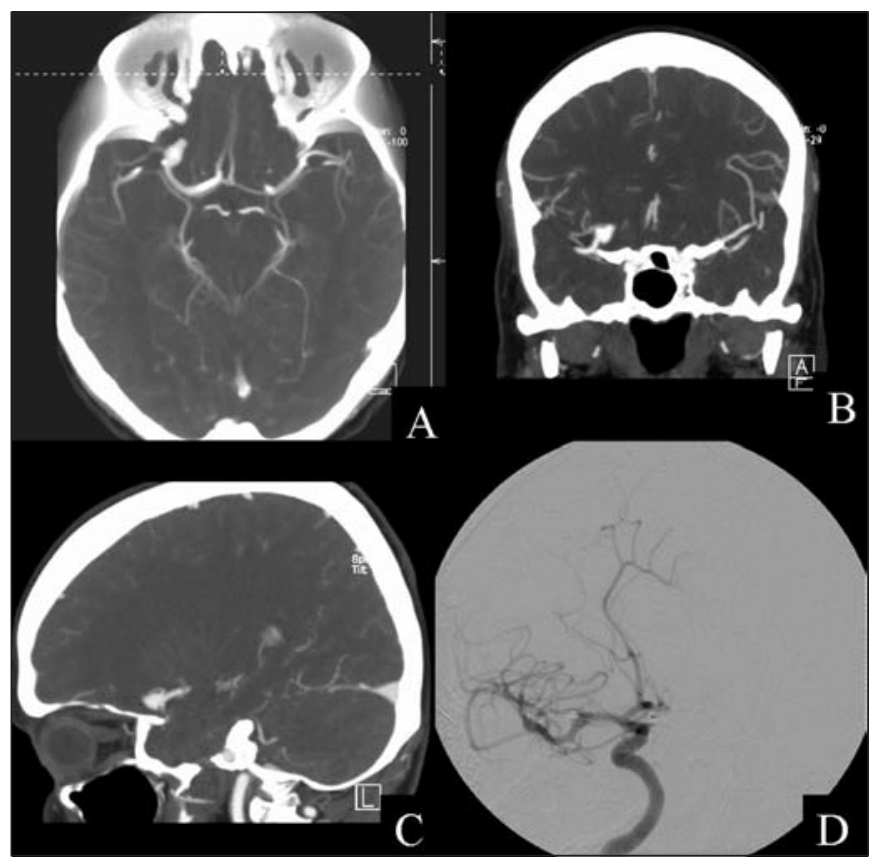

Figure 1: Patient 1. A to C) Pre operative cerebral computer tomography angiogram (CTA) showing right middle cerebral artery (MCA) bifurcation aneurysm. D) Post operative cerebral angiogram after clipping of the aneurysm.

laryngeal constriction and word finding difficulties, occurred less frequently, about once a month. The investigation demontrated an $11 \mathrm{~mm}$ left MCA bifurcation aneurysm imbedded in the insula. A symptom calendar over six weeks showed that paresthesiae were contralateral to the aneurysm $74 \%$ of time, ipsilateral in $21 \%$ and bilateral in 5\%. An EEG was normal. After surgical clipping of the aneurysm, the patient experienced a complete resolution of her symptoms over the four years since surgery, except for a single episode of paresthesia in the past year (Figure 2).
Case 3: A 50-year-old male presented with two episodes of perioral paresthesiae and painful right hemiparesthesiae lasting five minutes, one week apart. The MRI revealed a giant unruptured partially thrombosed aneurysm of the left MCA bifurcation (Figure 3). He was initially treated with aspirin for a suspected transient ischemic attack. The aneurysm was eventually treated successfully by endovascular coiling. During the three years of follow-up, the patient continued to experience similar episodes of paroxystic paresthesiae. The brain MRI remained unchanged and the EEG done during one episode was normal (Figure 3).

\section{Discussion}

The insula is a highly developed structure hidden deep within the Sylvian fissure and surrounded by the frontal, parietal and temporal opercula ${ }^{1}$. The insula is closely related to the middle cerebral artery, from which it receives its blood supply via 30 to 40 small arteries that spring from the M2 and M3 segments. The insula has wide connections with the neocortex, basal ganglia, thalamus, hypothalamus, limbic structures and olfactory cortex. These numerous connections subserve the complex functional spectrum of the insular lobe that include: (a) somatosensory functions; (b) auditory functions; (c) language functions; (d) a primary visceral/autonomic sensory and motor area, (e) and a supplementary motor area. ${ }^{2-15}$

We present uncommon manifestations of non-ruptured MCA aneurysms attributed to their location in the insula. Several series have been published on tumors, angiomas, and arteriovenous malformations in the insular regions ${ }^{16-25}$. We did not find any publication of aneurysms causing insular-related symptoms. All patients reported somatosensory symptoms. These were accompanied by autonomic (palpitations), visceral (nausea) and language disturbances in Patients 1 and 2 respectively. Somatosensory symptoms could affect one limb or the whole hemibody, mainly contralaterally but ipsilaterally or also bilaterally at times. Some painful limb paresthesias, throat constriction and perioral paresthesias were also frequently described. These symptoms are consistent with data found in the literature on direct stimulation of the human insular cortex using

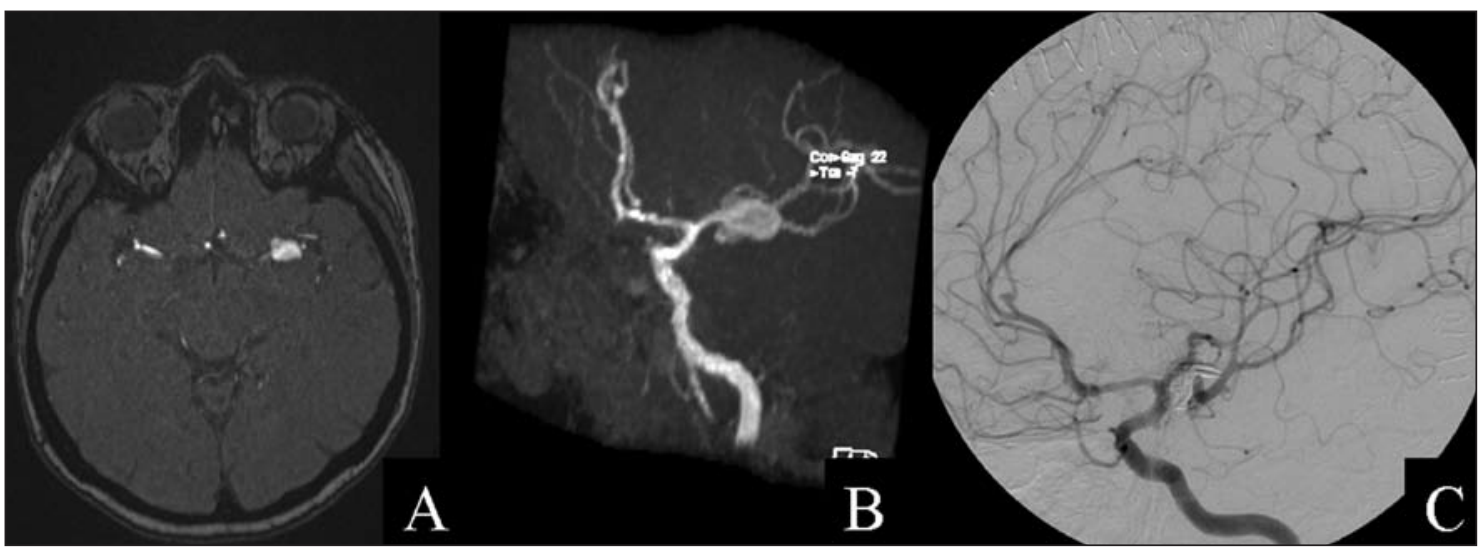

Figure 2: Patient 2. A and B) Pre operative cerebral magnetic resonance angiogram (MRA) showing left MCA bifurcation aneurysm. C) Post operative cerebral angiogram after clipping of the aneurysm. 


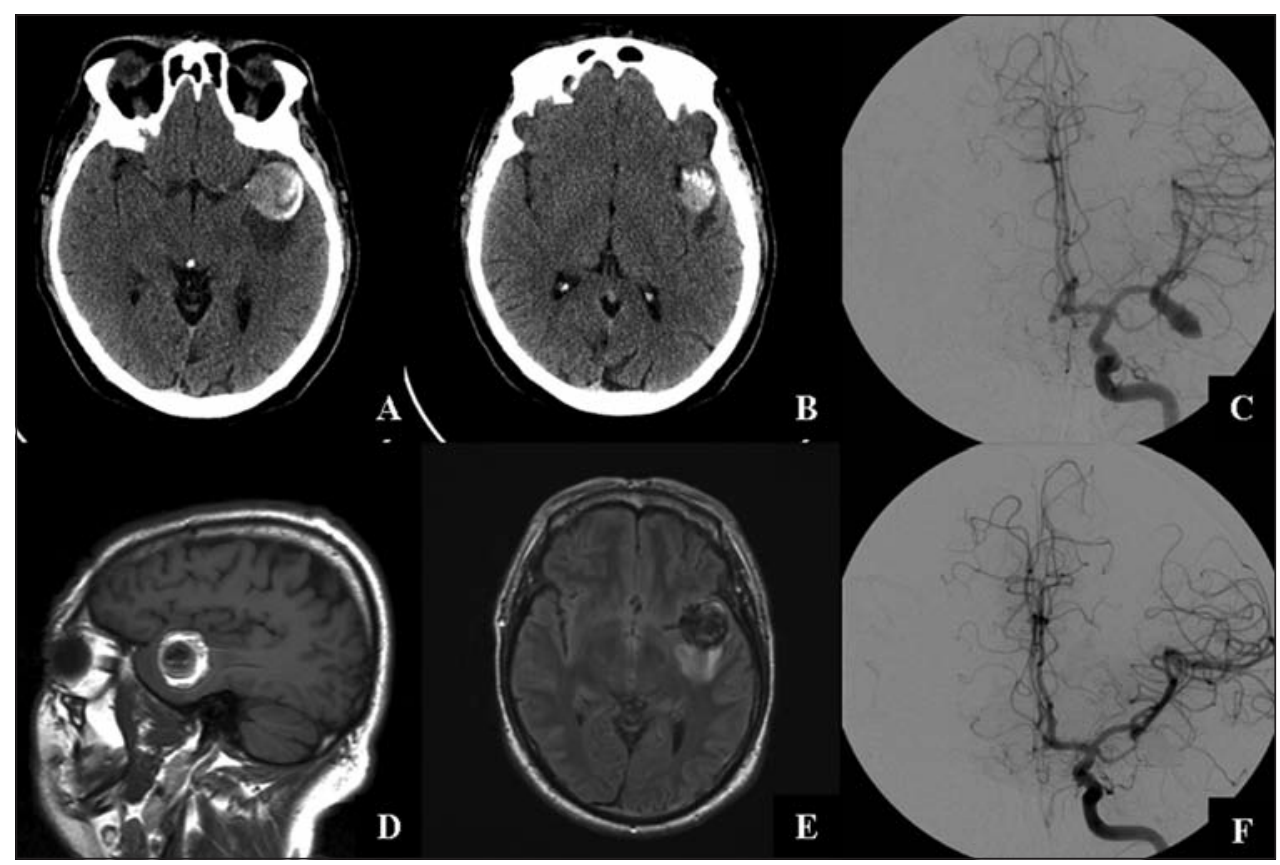

Figure 3: Patient 3. A and B) Pre operative cerebral CT scan and C) cerebral angiogram showing a large partially thrombosed left MCA bifurcation aneurysm producing a mass effect on the insula. $D$ and E) Post embolisation cerebral MRI and F) cerebral angiogram showing sub-total exclusion of the aneurysm and persistant mass effect on the insula.

intracerebral electrodes in epileptic patients. Our group ${ }^{26}$, similar to Penfield ${ }^{27,28}$ and Isnard et al, ${ }^{29,30}$ have shown that somatosensory symptoms were the most frequently evoked responses during human insular cortical stimulation, affecting restricted territories or larger areas, contralaterally, ipsilaterally or bilaterally. In addition, in the Isnard et al series, the majority of patients with seizures originating from the insula had the four cardinal ictal symptoms: perioral paresthesia, throat constriction and lateralized somatosensory or motor symptoms. ${ }^{29}$

In all the cases, the paresthesis was surprisingly bilateral, with symptoms being more important contra-lateral to the lesion. During electrical stimulation of the insular cortex in awake patients after temporal lobectomy, Penfield noted that sensations were usually contra-lateral, but were on occasion ipsilateral or bilateral $^{27}$. A similar observation was made by Isnard et al during stimulation by deep electrodes inserted in the insula, where $10 \%$ of somatosensory responses were ipsilateral and 5\% were bilateral $^{29,30}$. Other less-frequently evoked responses included viscerosensitive, motor, vestibular, auditory and language disturbances.

The exact mechanism by which vascular lesions in the insula become symptomatic is uncertain. Symptoms may be related to epileptic seizures or from direct mass effect. Embolic events or a vascular steal phenomena may be other possibilities. Epilepsy could be the mechanism in Patients 1 and 3 because symptoms were paroxystic and lasted only for a few minutes. Even though scalp EEG showed no epileptiform discharges during an event, this does not eliminate insular epilepsy. In a recent study, our group has shown that insular seizures (confirmed by intracerebral electrodes) could be missed by scalp EEG recordings possibly due to its deep-seated location ${ }^{26}$. We have also shown that lesions in the insula are highly epileptogenic ${ }^{31}$. For example, intractable epilepsy is found in $60 \%$ of low grade gliomas of the insula whereas it is found in only $15 \%$ of low grade gliomas in other cortical regions ${ }^{16}$. In Case 2, insular compression rather than epilepsy is likely the explanation for the long-lasting somatosensory symptoms (hours to days). In one report of a tumor located in the right insular cortex, the patient had a left arm sensory deficit that disappeared two months after tumor removal ${ }^{32}$. The author suggested that this may be due to mass effect.

\section{Conclusions}

Unruptured MCA bifurcation aneurysms can present with a combination of viscerosensitive, motor, language, autonomic and especially somatosensory symptoms. It is possible that these manifestations of symptomatic aneurysms are not uncommon. However, these symptoms may have been overlooked in the past. In addition to securing the aneurysm, dissecting it from the insula could result in symptom resolution.

\section{REFERENCES}

1. Türe U, Yasargil DCH, Al-Mefty O, Yasargil MG. Topographic anatomy of the insular region. J Neurosurg. 1999;90:720-33.

2. Augustine J. Circuitry and functional aspects of the insular lobe in primates including humans. Brain Res Rev. 1996;22:229-44.

3. Aziz Q, Anderson JLR, Valind S, Sundin A, Hamdy S, Jones AKP, et al. Identification of human brain loci processing oesophageal sensation using PET. Gastrenterology. 1997;113(1):50-9. 
4. Buchel C, Morris J, Dolan RJ, Friston KJ. Brain systems mediating aversive conditioning: an event related fMRI study Neuron. 1998;20(5):947-57.

5. Bucher SF, Dieterich M, Seelos KC, Brandt T. Sensorimotor cerebral activation during optokinetic nystagmus: a functional MRI study. Neurology. 1997;49:1370-7.

6. Burton H, Videen TO, Raichle ME. Tactile-vibration-activated foci in insular and parietal-opercular cortex studied with PET: mapping the second somatosensory area in humans. Somatosens Mot Res. 1993;10(3):297-308.

7. Cheung RT, Hachinski V. The insula and cerebrogenic sudden death. Arch Neur. 2000;57(12):1685-8.

8. Chollet F, Dipiero V, Wise RJS, Brooks DJ, Dolan RJ, Frackowiak RSJ. The functional anatomy of motor recovery after stroke in humans: a study with PET. Ann Neurol. 1991;29:63-71.

9. Colebatch JG, Deiber MP, Passingham RE, Friston KJ, Frackowiak RS. Regional cerebral blood flow during voluntary arm and hand movements in human subjects. J Neurophysiology. 1991;65: $1392-401$

10. Dupont S, Bouilleret V, Hasboun D, Semah F, Baulac M. Functional anatomy of the insula: new insights from imaging. Surg Radiol Anat. 2003;25:S113-9.

11. Ghaem O, Mellet E, Crivello F, Tzourio N, Mazoyer B, Berthoz A, et al. Mental navigation along memorized routes activates the hippocampus precuneus and insula. Neuroreport. 1997;8(3): 739-44.

12. Mesulam MM, Mufson EJ. The insula of Reil in man and monkey. Architectonics, connectivity, and function. In: Peters A, Jones EG, editors. Cerebral Cortex. Vol 4: Association and Auditory Cortices. New York: Plenum Press; 1985. p. 179-226

13. Rumsey JM, Horwitz B, Donohue BC, Nace K, Maisog JM, Andreason P. Phonological and orthographic components of word recognition: a PET-rCBF study. Brain. 1997;120(5): 739-59.

14. Seeck M, Zaim S, Chaves-Vischer V, Blanke O, Maeder-Ingvar M, Weissert $\mathrm{M}$, et al. Ictal bradycardia in a young child with focal cortical dysplasia in the right insular cortex. Eur J Ped Neur. 2003;7(4):177-81

15. Xu X, Fukuyama H, Yazawa S, Mima T, Hanakawa T, Magata Y, et al. Functional localization of pain perception in the human brain studied by PET. Neuroreport. 1997;8(2):555-9.

16. Bertalanffy H, Gilsbach JM, Eggert HR, Seeger W. Microsurgery of deep-seated cavernous angiomas: report of 26 cases. Acta Neurochir. 1991;108:91-9.

17. Duffau H, Capelle L, Lopes M, Bitar A, Sichez JP, Van Effenterre R. Medically intractable epilepsy from insular low-grade gliomas: improvement after an extended lesionectomy. Acta Neurochir. 2002;144(6):563-72.
18. Heffez DS. Stereotactic transsylvian, transinsular approach for deep-seated lesions. Surg Neurol. 1997;48:113-24.

19. Lang FF, Olansen NE, DeMonte F, Gokaslan ZL, Holland EC, Kalhorn C, et al. Surgical resection of intrinsic insular tumors: complication avoidance. J Neurosurg. 2001;95(4):638-50.

20. Meyer FB, Bates LM, Goerss SJ, Friedman JA, Windschitl WL, Duffy JR, et al. Awake craniotomy for aggressive resection of primary gliomas located in eloquent brain. Mayo Clinic Proc. 76 (7):677-87.

21. Tirakotai W, Sure U, Benes L, Krischek B, Bien S, Bertalanffy H. Image-guided transsylvian, transinsular approach for insular cavernous angiomas. Neurosurg. 2003; 53(6):1299-304.

22. Vanaclocha V, Saiz-Sapena N, Garcia-Casasola C. Surgical treatment of insular gliomas. Acta Neurochir. 1997;139(12): 1126-34.

23. Yasargil MG, von Ammon K, Cavazos E, Doczi T, Reeves JD, Roth P. Tumors of the limbic and paralimbic systems. Acta Neurochir. 1992;118:40-52.

24. Zentner J, Meyer B, Stangl A, Schramm J. Intrinsic tumors of the insula: a prospective surgical study of 30 patients. J Neurosurg. 1996;85 (2):263-71.

25. Zimmerman G, Lewis AI, Tew JM. Pure sylvian fissure arteriovenous malformations. JNS. 2000;92(1):39-44.

26. Nguyen DK, Nguyen DB, Malak R, Leroux JM, Carmant L, SaintHilaire JM, et al. Revisiting the role of the insula in refractory partial epilepsy. Epilepsia. 2009;50(3):510-20.

27. Penfield W, Faulk MJ. The insula: further observations on its functions. Brain. 1955;78:445-70.

28. Penfield W, Jasper H. Epilepsy and the functional anatomy of the human brain. Boston: Little Brown; 1954

29. Isnard J, Guenot M, Sindou M, Mauguiere F. Clinical manifestations of insular lobe seizures: a stereoelectroencephalographic study. Epilepsia 2004;45(9):1079-90.

30. Ostrowsky K, Isnard J, Ryvlin P, Guénot M, Fischer C, Mauguière F. Functional mapping of the insular cortex: clinical implication in temporal lobe epilepsy. Epilepsia. 2000;41:681-6.

31. Malak R, Bouthillier A, Carmant L, Cossette P, Giard N, SaintHilaire JM, et al. Microsurgery of epileptic foci in the insular region. JNS. 2009; 110:1153-63.

32. Greenspan JD, Winfield JA. Reversible pain and tactile deficits associated with a cerebral tumor compressing the posterior insula and parietal operculum. Pain. 1992;50(1):29-39. 